\title{
Correction
}

\section{Correction: Role of Alternative Polyadenylation during Adipogenic Differentiation: An In Silico Approach}

\section{The PLOS ONE Staff}

The legends for Figure 2 and Figure 3 are incorrectly switched.

Please see the complete, corrected Figure 2 here.

A

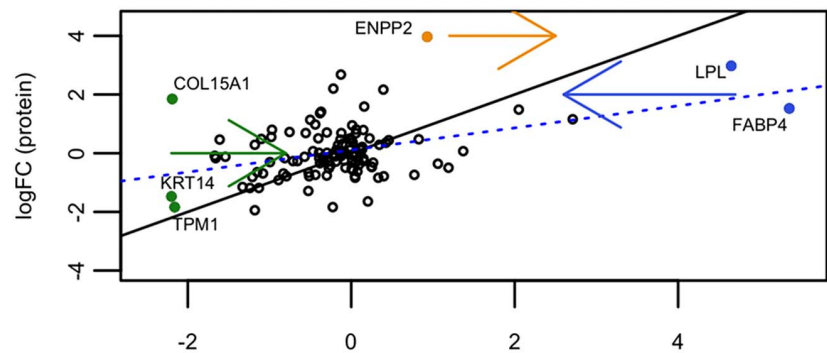

$\log \mathrm{FC}(\mathrm{mRNA})$

B

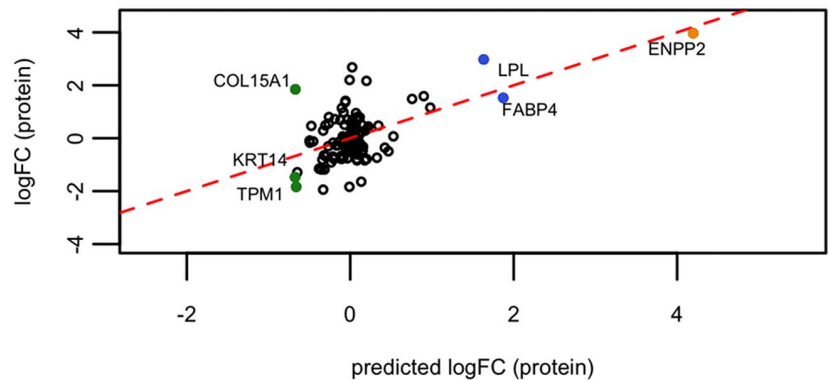

C

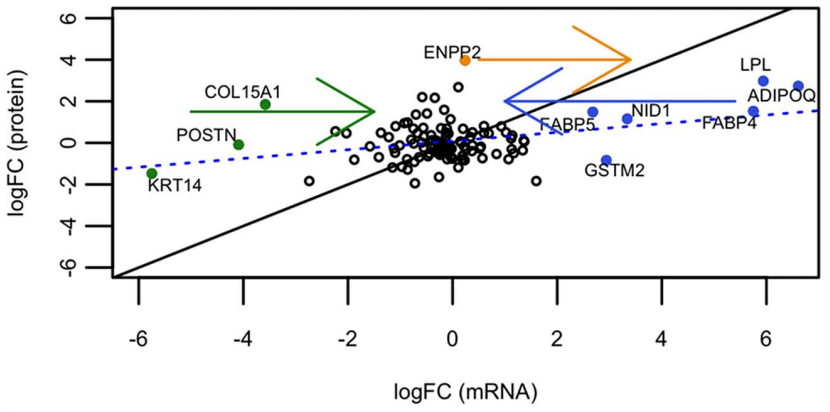

D

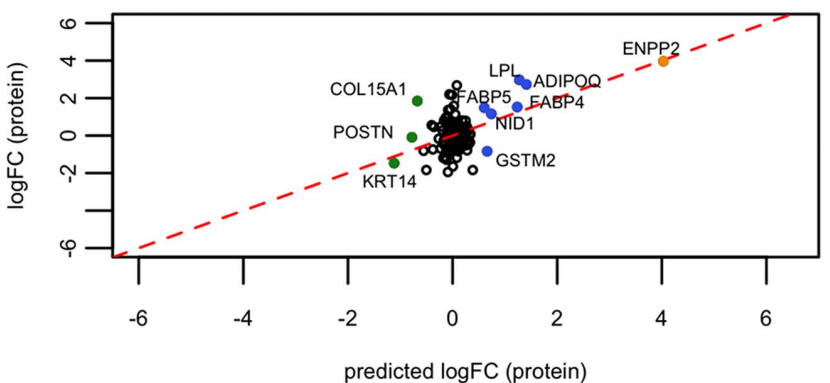

Figure 2. Linear models for day 5 secreted proteins represented graphically. (A, B) Polysomal fraction, (C, D) total RNA. (A) and (C): plot representing $\log \mathrm{FC}_{\mathrm{mRNA}}$ against $\log \mathrm{FC}_{\text {protein. }}$. The dashed blue line is the best fitting line of the base model, $\log F \mathrm{C}_{\text {protein }}$ against log $\mathrm{FC} \mathrm{C}_{\mathrm{mRNA}}$. The straight black line is the identity line (so you get an idea of the real coefficient of the model). The colored full dots are genes, which are moved after applying the model with miRNAs. Hence, they represent genes that are better explained by our model. The arrows indicate the direction of the movement. (B) and (D): plot representing our linear model including miRNA effect. In this case, the best (multivariate) model is shown: miR-130b and miR-558 (polysomal) and miR-150* (total). Full dots are the genes that were corrected by our model, being now closer to the protein prediction line of the model (red full line). Black identity line concurs with the red line. Note that the abscissas of (A) and (C) seem to have a compression of range with

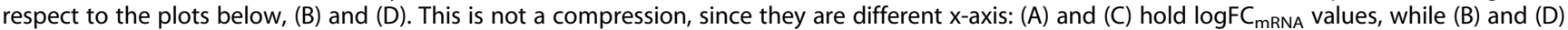
$\log \mathrm{FC}_{\text {protein. }}$.

doi:10.1371/journal.pone.0075578.g002

Citation: The PLOS ONE Staff (2014) Correction: Role of Alternative Polyadenylation during Adipogenic Differentiation: An In Silico Approach. PLoS ONE 9(5): e91409. doi:10.1371/journal.pone.0091409

Published May 30, 2014

Copyright: ( 2014 The PLOS ONE Staff. This is an open-access article distributed under the terms of the Creative Commons Attribution License, which permits unrestricted use, distribution, and reproduction in any medium, provided the original author and source are credited. 
Please see the complete, corrected Figure 3 here.

A

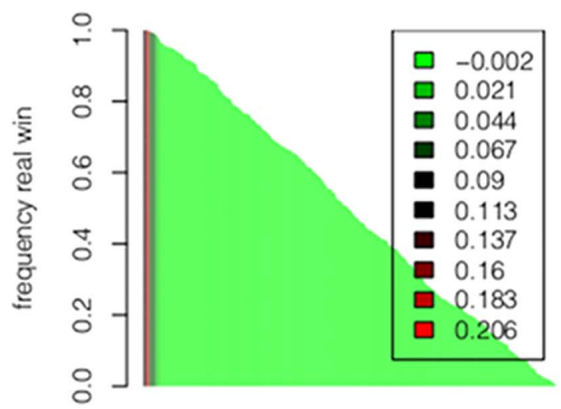

C

NUCLEAR POLY

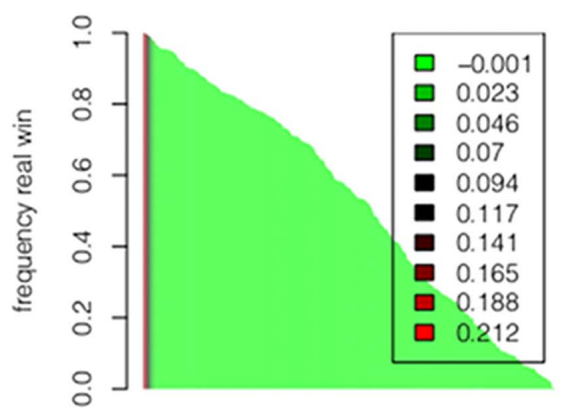

B

SECRETOME TOTAL

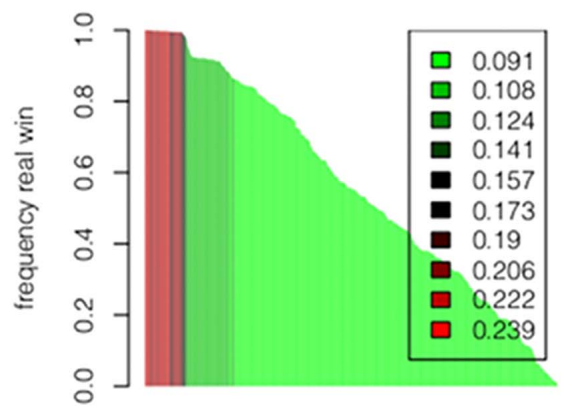

D

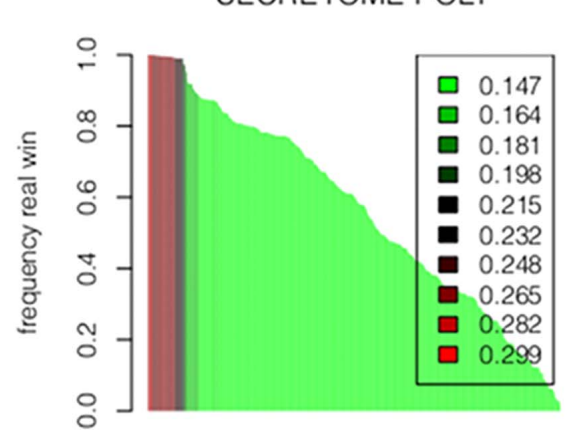

Figure 3. Bootstrap to asses our results for each RNA fraction and each protein set. Bootstrap results for total RNA fractions are shown in $A$ (nuclear) and B (secretome). Polysomal fraction is shown in C (nuclear) and D (secretome). For each such pair of conditions, we performed a bootstrap analysis as explained in 6 . For each miRNA we permute the values of the genes and calculate the explained variance from the resulting linear model. This procedure is repeated 1000 times. The $y$-axis represents how many times the "true" miRNA wins over the random model. The x-axis represents all miRNAs. The colors, from red to green, represent the explained variance from the current "true" model. It can be observed that the miRNAs win almost all times (the larger bars, almost reaching 1), explain the larger variance, and hence produce the best models (red). doi:10.1371/journal.pone.0075578.g003

\section{Reference}

1. Spangenberg L, Correa A, Dallagiovanna B, Naya H (2013) Role of Alternative Polyadenylation during Adipogenic Differentiation: An In Silico Approach. PLoS ONE 8(10): e75578. doi:10.1371/journal.pone.0075578 